\title{
Acute obstructive hydrocephalus as a complication of diabetic ketoacidosis in a child with prior communicating hydrocephalus
}

\author{
*Kamalatheepan Sellappillai ${ }^{1}$, Jithangi Wanigasinghe ${ }^{2}$, Manouri P Senanayake ${ }^{2}$
}

Sri Lanka Journal of Child Health, 2017; 46(3): 288-290

DOI: http://dx.doi.org/10.4038/sljch.v46i3.8336

(Key words: Diabetic ketoacidosis, cerebral oedema, obstructive hydrocephalus)

Cerebral oedema is the most common reason for neurological deterioration in a patient with diabetic ketoacidosis (DKA), but if neurological deterioration persists despite improvement of the DKA, other possibilities need consideration. We present a 10 year old girl, who presented with DKA with persistent reduced consciousness due to acute onset obstructive hydrocephalus secondary to aqueduct stenosis complicating DKA.

\section{Case report}

A 10 year old girl was transferred for management of DKA following wound sepsis. She was diagnosed with diabetes mellitus (DM) two years ago and was on regular Mixtard insulin. This was her first admission with DKA. She was febrile, mildly dehydrated with a respiratory rate of $26 / \mathrm{min}$, a heart rate $130 / \mathrm{min}$ and a blood pressure 120/90 mmHg. The Glasgow Coma Scale (GCS) was 15. Her random blood glucose was $20.3 \mathrm{mmol} / \mathrm{L}$ and urine was positive for ketones. White blood cell count was $35.4 \times 10^{3} / \mu 1$ with neutrophilia of $70 \%$. Haemoglobin was $13.3 \mathrm{mg} / \mathrm{dl}$ and platelet count $300,000 \times 10^{3} / \mu 1$. Arterial blood gas showed a $\mathrm{pH}$ of 7.131 , a base deficit of $20 \mathrm{mEq} / \mathrm{L}$, and $\mathrm{a} \mathrm{pCo}_{2}$ of $18 \mathrm{mmHg}$. The blood urea was $8.2 \mathrm{mmol} / \mathrm{L}$ and creatinine $102 \mu \mathrm{mol} / \mathrm{L}$. Her serum electrolytes were normal. She was treated according to the local DKA guideline $^{1}$. Broad spectrum antibiotics were added.

In the past, she had been treated for meningoencephalitis at the age of two years. Neuroimaging done at that time showed a small right sided infarction and mild-moderate ventriculomegaly (Figure 1).

\footnotetext{
${ }^{1}$ Anuradhapura Teaching hospital, ${ }^{2}$ University of Colombo, Sri Lanka,

*Correspondence: kamalatheepan@yahoo.com (Received on 25 April 2016: Accepted after revision on 17 June 2016)

The authors declare that there are no conflicts of interest

Personal funding was used in formulating the article.

Open Access Article published under the Creative

Commons Attribution CC-BY (cC) (i)
}

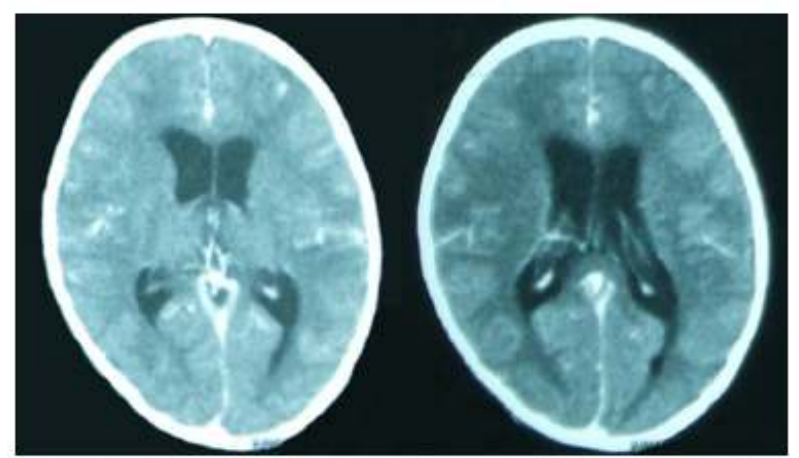

Figure 1: CT appearance of mild to moderate dilatation of lateral ventricles at the age of 2 years

Although she had a setback in the development initially, she recovered well later. Now she attends normal school but has difficulties in maintaining satisfactory academic performance.

With treatment her hyperglycaemia and the associated biochemical changes improved gradually. However, her level of consciousness began to deteriorate from GCS of 15 on admission to $9 / 15$ over the next 12 hours. She was treated with osmotic therapy and neuro-protection measures for suspected cerebral oedema and later with intensive care for management of raised intracranial pressure and critical care monitoring.

Due to this poor improvement of level of consciousness computed tomography (CT) of brain was performed. This revealed an obstructive hydrocephalus with dilated lateral ventricles and normal size $4^{\text {th }}$ ventricle indicating a possible aqueduct stenosis. Due to poor improvement of her conscious status, she underwent external ventricular drainage but with little benefit. Eventually, she had a ventricular peritoneal shunt inserted and this resulted in gradual improvement of her conscious status to normal. She was discharged after two weeks with no further problems. MRI of brain confirmed the aqueduct stenosis (Figure 2).

She has been followed up regularly over the past three years. She is back in school and continuing without any further complications. 


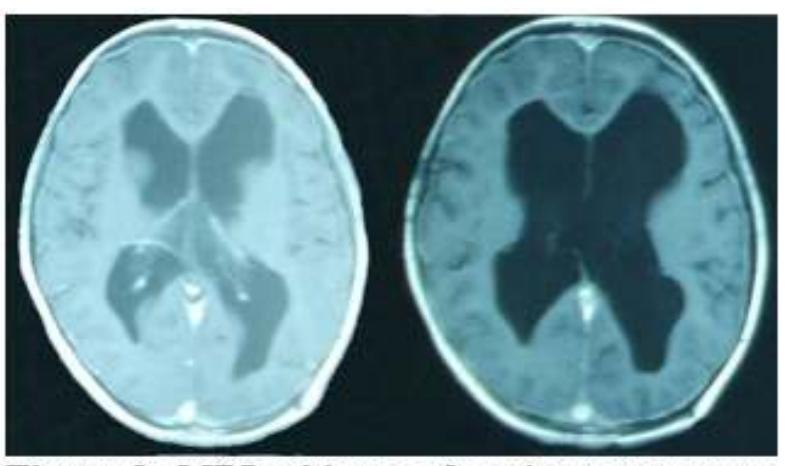

Figure 2: $M R I$ evidence of moderate to severe enlargement of the lateral ventricles following admission with DKA

\section{Discussion}

Insulin dependent diabetes is a growing problem in children. DKA is the most feared life threatening emergency and the leading cause of death in a child with diabetes ${ }^{2}$. DKA is defined as serum glucose concentration more than $300 \mathrm{mg} / \mathrm{dl}$, blood bicarbonate less than $15 \mathrm{mmol} / \mathrm{L}$, venous $\mathrm{pH}$ less than 7.25 and the presence of ketones in the urine $e^{3,4}$. One important challenge in DKA is the vulnerability to intracerebral complications and the subsequent neurological deterioration. The recognized causes for neurological deterioration are cerebral oedema, cerebral infection, cerebrovascular accidents and basilar oedema ${ }^{5,6}$. Among these, cerebral oedema is the foremost significant contributor to mortality and morbidity in children with $\mathrm{DKA}^{7,8}$. The overall risk of developing cerebral oedema is 6.8 per 1000 episodes of DKA in children under 16 years in the $\mathrm{UK}^{6}$ and is much higher in those newly diagnosed with DM. Cerebral oedema is also responsible for majority of diabetes-related deaths in children ${ }^{2}$.

Obstructive hydrocephalus developing in a child with DKA is an extremely rare occurrence. Only a few cases have been reported in the past. Hayes PC and Newton RW described a case of reversible internal hydrocephalus during an episode of $\mathrm{DKA}^{8}$. Eskander et al reported on an 11 year old presenting with new onset insulin dependent DM and DKA ${ }^{9}$. Though he was initially responsive, like our patient he became unresponsive after gradual correction of the DKA. The CT scanning demonstrated obstructive hydrocephalus resulting from focal cerebellar and brainstem oedema ${ }^{10}$. Gruber $\mathrm{TJ}^{11}$ described a similar situation to ours in a child with a previous neurological insult, where a 15 year old with shunt placement following repair of a myelomeningocele, presented with transient new onset ventriculomegaly in association with DKA.

Our patient had an asymptomatic, mild communicating hydrocephalus following the right side temporal lobe infarction she sustained many years ago. On top of this she developed hydrocephalus due to aqueduct stenosis. Several pathophysiological mechanisms can explain the occurrence of aqueduct stenosis. First, the presence of brainstem oedema can compress the aqueduct and thus the obstructive hydrocephalus. Though the CT imaging of this child failed to show gross cerebral oedema, we are aware of its limitation in showing the presence of brainstem oedema. Localized cerebral oedema in the absence of generalized oedema in DKA has been previously described ${ }^{6}$. Rosenbloom reported that $8-10 \%$ of instances of clinically apparent generalized cerebral oedema will be associated with localized basilar oedema $^{7}$. The reasons for this different type of oedema may be related to DKA being related to more vasogenic (blood brain barrier) than cytotoxic oedema ${ }^{5}$. Further, recent studies show that in DKA, there are regional increases in the blood-brain-barrier permeability ratio ${ }^{12}$. These evidences may partly explain the reasons for the development of aqueduct stenosis due to possible localized oedema in the brainstem region causing aqueduct narrowing and obstructive hydrocephalus. Another possible explanation for development of aqueduct stenosis in this child is the hypothesis suggested by McMillon $\mathrm{JJ}$ and Williams $\mathrm{B}^{13}$ who suggested that non tumorous aqueduct stenosis is more likely to be the result of hydrocephalus. As in this child who had communicating hydrocephalus earlier, the lateral ventricles can enlarge as a result of intracellular volume loss due to hyperglycemia ${ }^{10}$. This is also the likely explanation outlined in the case of transient ventriculomegaly in a child with hypernatremia ${ }^{14}$. The sudden development of enlarging hydrocephalus causes the under surface of the temporal lobes to move downwards. With the depression of the tentorium the upper brain stem becomes more vulnerable to compression and producing aqueduct stenosis ${ }^{13}$.

This case highlights that different complex mechanisms result in different intracerebral insults in a child with DKA. Evaluating for other causes for acute neurological deterioration beside cerebral oedema is recommended when the standard treatment is unresponsive. 


\section{References}

1. Ministry of Healthcare and Nutrition, Sri Lanka. Paediatric emergencies. National Guidelines 2007; 18:8-21

2. Edge JA, Ford-Adams ME, Dunger DB. Causes of death in children with insulin dependent diabetes 1990-96. Archives of Disease in Childhood 1999; 81:318-23.

https://doi.org/10.1136/adc.81.4.318

PMid: 10490436 PMCid: PMC1718106

3. Glaser N, Barnet P, McCaslin I, et al. Risk factors for cerebral edema in children with diabetic ketoacidosis. New England Journal of Medicine 2001; 344(4):264-9. https://doi.org/10.1056/NEJM200101253440 404

PMid: 11172153

4. Josephine Ho, Daniele Pacuad, Michael de Hill, Catherine Ross and et al. Diabetic ketoacidosis and paediatric stroke. Canadian Medical Association Journal 2005; 172(3): 327-8.

https://doi.org/10.1503/cmaj.1032013

PMid: 15684112 PMCid: PMC545752

5. Levin DL. Cerebral oedema in diabetic ketoacidosis. Paediatric Critical Care Medicine 2008; 9(3):320-9.

https://doi.org/10.1097/PCC.0b013e31816c7

082

PMid: 18446108

6. Rosenbloom AL. Intracerebral crises during treatment of diabetic ketoacidosis. Diabetes Care 1990; 13:22-33.

https://doi.org/10.2337/diacare.13.1.22

PMid: 2105195

7. Edge JA, Hawkins MM, Winter DL, Dunger DB. The risk and outcome of cerebral oedema developing during diabetic ketoacidosis. Archives of Disease in Childhood 2001; 85:16-22.

https://doi.org/10.1136/adc.85.1.16

PMid: 11420189 PMCid: PMC1718828

8. Hayes PC, Newton RW. Reversible internal hydrocephalus complicating diabetic ketoacidosis. Scottish Medical Journal 1984; 29(3):195-7. https://doi.org/10.1177/00369330840290031

4

PMid: 6442799

9. Eskandar EN, Weller SJ, Frim DM. Hydrocephalus requiring urgent external ventricular drainage in a patient with diabetic ketoacidosis and cerebral oedema: case report. Neurosurgery 1997; 40(4): 836-9.

https://doi.org/10.1097/0000612319970400000035

PMid: 9092859

10. Gruber TJ, Rozzelle CJ. Transient ventriculomegaly in an adolescent presenting with shunted hydrocephalus, diabetic ketoacidosis, and hyperglycaemia. Pediatric Neurosurgery 2008; 44(6):496-500. https://doi.org/10.1159/000187124 PMid: 19127093

11. Brown TB, Cerebral oedema in childhood Diabetic ketoacidosis: is treatment a factor? Emergency Medicine Journal 2004; 21(2): 141-4.

https://doi.org/10.1136/emj.2002.001578

PMid: 14988335 PMCid: PMC1726262

12. Vavilala MS, Richards TL, Roberts JS, Chiu H. Change in blood-brain barrier permeability during paediatric diabetic ketoacidosis treatment. Pediatric Critical Care Medicine 2010; 11(3):332-8.

PMid: 19838141 PMCid: PMC2913885

13. McMillon JJ, Williams B. Aqueduct stenosis. Journal of Neurology, Neurosurgery and Psychiatry 1977; 40: 521-32.

https://doi.org/10.1136/jnnp.40.6.521

14. Fahrbach J, Rozzelle CJ. Transient ventriculomegaly in a child presenting with hypernatraemia. Journal of Neurosurgery 2006; 104(supplement 3):192-4.

PMid: 16572637 